\title{
Determinants of Use of Health and Wellness Products by People in Chandigarh and Shimla
}

\author{
Divya Sharma ${ }^{1}$, Amarjeet Singh ${ }^{2}$
}

\begin{abstract}
Background: Health has always been given importance in all cultures. Various new dimensions have been added to the concept of health with time. This in turn has led to change of perception and beliefs regarding health among people.

Aim and objective: To analyze the determinants of use of health and wellness products by people in Chandigarh and Shimla.

Materials and methods: This quantitative cross-sectional study was conducted on a total of 150 individuals from Chandigarh and Shimla (H.P) using semi-structured interview schedules. The sample was further divided in a ratio of 2:1 because of the difference in area and population of Chandigarh and Shimla. A health and wellness score was calculated. The data were analyzed statistically by calculating frequencies, percentages, and using the Chi-square test.

Results: The mean health and wellness product usage score was 51 with a standard deviation of 11.8. There was a significant relation of gender with product usage. Being physically fit was the main definition of health and wellness for the majority of participants. A proper and healthy diet was the main focus of a large number of participants to stay healthy. The most commonly used source of information to learn about health and wellness by participants was the Internet. The most important criterion for purchasing health and wellness products reported by the majority of participants was their perceived effectiveness.

Conclusion: The use of products was seen among all age-groups. The factor that affected the use of these products was gender. Females were using more health and wellness products than males.

Keywords: Fitness, Health, Wellness, Wellness products.

Journal of Postgraduate Medicine, Education and Research (2021): 10.5005/jp-journals-10028-1452
\end{abstract}

\section{INTRODUCTION}

Health has always been given priority in all cultures since ancient times. In India, traditional medicine and preventive practices have always stressed: "a healthy mind in a healthy body".1 The concept of health is old but various new dimensions have been added to it with time. The change in disease patterns from communicable diseases to non-communicable diseases has also changed the way people deal with their health-related issues. Changing the lifestyle of people in the wake of westernization has led to the advent of new market products that exploit the prevailing concept of wellness. The increasing prevalence of the non-communicable disease has resulted in a renewed focus on preventive care. Wellness is now becoming an integral part of this shift. ${ }^{2}$

The most important contribution to the "wellness revolution" is the media explosion. There is a focus on health and wellness in every possible form of media like electronic and print format, e.g., specialty magazines, newsletters, books, and a plethora of websites and television programs.

In modern society, health is creeping into all aspects of life. It is being projected as a "purchasable commodity". ${ }^{3}$ Adoption of the health backdrop by various product brands has led to intensive marketing of health products. The concept of wellness is modifying industries like food, beverage, and travel. The wellness industry includes the products and services that promote being healthy rather than just responding to illness. ${ }^{4}$ This industry in India has evolved rapidly from its nascent unstructured beginning in the early 1990 s to a comprehensive ecosystem today. ${ }^{5}$

The reasons behind the increased popularity of the wellness movement and its becoming so huge are many. The most important

\begin{abstract}
1,2Department of Community Medicine and School of Public Health, Postgraduate Institute of Medical Education and Research, Chandigarh, India

Corresponding Author: Divya Sharma, Department of Community Medicine and School of Public Health, Postgraduate Institute of Medical Education and Research, Chandigarh, India, Phone: +91 9876710228, e-mail: divya2809.sharma@gmail.com

How to cite this article: Sharma D, Singh A. Determinants of Use of Health and Wellness Products by People in Chandigarh and Shimla. J Postgrad Med Edu Res 2021;55(4):155-159.
\end{abstract}

Source of support: Nil

Conflict of interest: None

reason is the widespread presence of chronic diseases associated with an unhealthy lifestyle which had a negative impact on healthcare systems and economies throughout the world. This has resulted in forcing the governments to shift their focus to prevention and wellness.

The increased consumer awareness and wellness consciousness is encouraging the industry to change the marketing of products. The other reasons for the shift include a greater focus on fitness, higher personal incomes, and the urbanization of emerging economies. All these factors have contributed to the formation of a consumer-focused healthcare products market.

As consumer demands for wellness products and services continue to evolve in India, growing income levels and increasing awareness have triggered a change in aspirations and behavior. Health and wellness, which till recently were a relative niche concept

(c) The Author(s). 2021 Open Access This article is distributed under the terms of the Creative Commons Attribution 4.0 International License (https://creativecommons. org/licenses/by-nc/4.0/), which permits unrestricted use, distribution, and non-commercial reproduction in any medium, provided you give appropriate credit to the original author(s) and the source, provide a link to the Creative Commons license, and indicate if changes were made. The Creative Commons Public Domain Dedication waiver (http://creativecommons.org/publicdomain/zero/1.0/) applies to the data made available in this article, unless otherwise stated. 
targeting a select few, are now reaching to mainstream audience. ${ }^{6}$ Consumers today want to take control of how they look and feel. This is influencing the purchase of products across categories such as food, beverages, and personal care.

The choices made by the people regarding their health are affected by various factors (personal, society, and market related). Hence, it is important to study the factors influencing people's health maintenance. The behavior of people related to the trends being followed by them regarding the use of health products also needs scrutiny.

\section{Aim and Objective}

To analyze the determinants of use of health and wellness products by people in Chandigarh and Shimla.

\section{Materials and Methods}

This quantitative cross-sectional study was carried out in Sector 15 Chandigarh, UT and Sanjauli, Shimla (H.P). The areas were selected purposively. A total of 150 participants were included in the study. The sample was further divided in a ratio of 2:1 because of the difference in area and population of Chandigarh and Shimla. A sample of 100 participants from Chandigarh and 50 from Shimla was taken. The participants were randomly selected from shops, markets, parks, and gyms. Data were collected on random days and in the evenings when the markets, gyms, and parks are crowded. Individuals above the age of 18 years and residing in the study areas were randomly selected in the markets. Participation was entirely voluntary and written consent was taken from the participants. The data were collected by the researcher using a semi-structured interview schedule. The tool was divided into three sections. The first section was demographic profile, the second section obtained information on family background and history, and the third section was factors and beliefs about health. There were 100 health and wellness products and each of them was scored as one. Scores were allotted to each segment of health and wellness products out of 100. The data scores of individuals were divided into three subgroups: low $(\leq 40)$, average (41-60), and high (61-100). The data obtained were coded and entered in MS Excel 2007. Redundant data were removed by cross-checking. The data were analyzed statistically by calculating frequencies, percentages, and using the Chi-square test.

\section{Results}

A total of 150 participants were included in the study. The participants between the age group of 18 to 25 years (34.6\%) were more. The number of female participants (51\%) was slightly more than males (48.6\%). There were $56 \%$ participants with graduation and below degree and $44 \%$ with higher degrees. More than half (52.6\%) participants were students followed by professionals (14\%) and people with private jobs (12.6\%). Participants belonging to middle-income families (43\%) were slightly more than those belonging to high-income families (38\%).

According to respondents, being physically fit (82\%) was the number one definition of health and wellness. The respondents also gave more importance to being happy and cheerful (59\%) and feeling good about oneself (55\%) when compared with other meanings of health and wellness. The factors that affected health according to the majority of participants were diet (59\%) and environment (55\%). The factor which was given the least importance was religion (12\%) (Table 1).
Table 1: View on health and wellness as reported by respondents $(n=150)$

\begin{tabular}{lc}
\hline Meaning of health and wellness & No. (\%)* \\
\hline Being physically fit & $123(82)$ \\
Being happy and cheerful & $88(59)$ \\
Feeling good about myself & $82(55)$ \\
Leading a balanced life & $77(51)$ \\
Being tension-free & $73(49)$ \\
Maintaining a spiritual balance & $65(43)$ \\
Having the energy for an active lifestyle & $63(42)$ \\
Not being ill & $57(38)$ \\
Being alert and bright-minded & $52(35)$ \\
Being able to deal with stress & $48(32)$ \\
Not being overweight & $44(29)$ \\
\hline Factors affecting health & No. (\%)* \\
\hline Diet & $89(59)$ \\
Environment (physical, housing, hygienic & $83(55)$ \\
conditions) & $75(50)$ \\
Genes & $68(45)$ \\
Physical activity & $57(38)$ \\
Status (education, money, occupation) & $41(27)$ \\
Family and friends & $32(21)$ \\
Recreation & $18(12)$ \\
Religion &
\end{tabular}

*Multiple responses were also given

A proper and healthy diet (70\%) was the main focus of respondents to stay healthy. The other activities which were performed by many respondents included maintaining hygiene (52\%), physical activities (48\%), and staying happy (46.6\%) (Fig. 1).

The most commonly used source of information to learn about health and wellness by respondents was the Internet (70\%) followed by family members (34\%). Health trainers (6\%), books/magazines (5\%), and nutritionists (4\%) were among the least used sources of information (Table 2).

The majority of the respondents bought health and wellness products from departmental and grocery stores (93\%). The other commonly used places for buying health and wellness products included marts (20.6\%) and online stores (14.6\%).

The most important criterion for purchasing health and wellness products reported by respondents was the effectiveness (64\%) of the product. The other criteria important to respondents included purity (54\%) and price (52.6\%) of products (Fig. 2).

The mean health and wellness product usage score was 51 with a standard deviation of 11.8. Using the Chi-square test a significant relation of product usage was seen with educational qualification, gender, and place of residence. A significantly more number of females (33.7\%) when compared with males (4\%) reported high product usage $\left(\chi^{2}=21.133, p\right.$ value $\left.=0.000\right)$. There was a significant relationship between educational qualification and product usage. A greater number of individuals with a post-graduation degree and above (27\%) when compared with individuals who were graduates and below (13\%) reported high product usage $\left(\chi^{2}=4.767, p\right.$ value $=$ 0.029). Individuals belonging to Chandigarh reported significantly lower product usage when compared with those belonging to Shimla $\left(\chi^{2}=8.972, p\right.$ value $\left.=0.011\right)$ (Table 3$)$. 


\section{Discussion}

Good health is central to human happiness and well-being. It is an ongoing process and can only be maintained by the regular efforts of an individual. A healthy person is capable of living life to its fullest potential. Being healthy is not only confined to the physical wellbeing of a person but also to mental stability and social well-being.

Nowadays, health is invading all spheres of life. People are developing a holistic view of wellness. They are participating in the wellness revolution to experience a quality life. Globalization increased disposable incomes, and exposure to western culture has led to high awareness levels in consumers, especially among youth. ${ }^{7}$ Consumers are getting attracted to the growing culture of fitness and looking beautiful.

The purchasing behavior of consumers reflects that health is equated by them with money. ${ }^{3}$ This observation is being ardently exploited by the markets. Every other product we come across in our daily life is being sold as an entity with health-enhancing quality. They are giving consumers the impression that spending more money will make them healthier.

The use of health and wellness products by people is based on various factors. These include their health beliefs, activities, and information source used to learn about these products. All these factors get converted to their criteria for buying such products. In this study, the meaning of health and wellness reported by most of the participants (82\%) was being physically fit. This depicts the increasing trend of fetish for fitness among people. Physical fitness was given more importance over mental health and happiness by participants. The fitness trend is also confirmed by the fact that

Table 2: Information sources used to learn about health and wellness $(n=150)$

\begin{tabular}{lc}
\hline Source of information & No. using; (\%)* \\
\hline Internet & $105(70)$ \\
Family members & $51(34)$ \\
Newspapers & $49(33)$ \\
Commercials & $36(24)$ \\
Friends/colleagues & $30(20)$ \\
Doctors & $27(18)$ \\
TV/radio shows & $25(17)$ \\
Blogs & $12(8)$ \\
Teachers & $11(7)$ \\
Health/ club trainers & $9(6)$ \\
Books/magazine & $8(5)$ \\
Nutritionist/dietician & $6(4)$ \\
\hline
\end{tabular}

*Multiple responses were also given

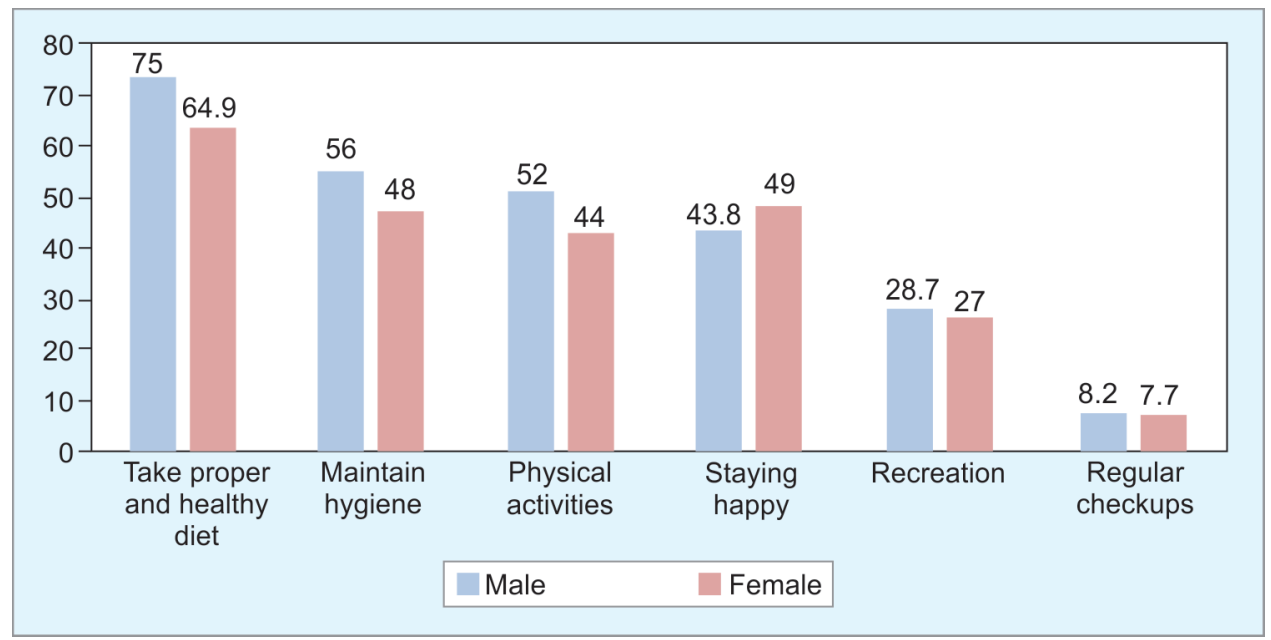

Fig. 1: Regular activities performed by respondents to stay healthy

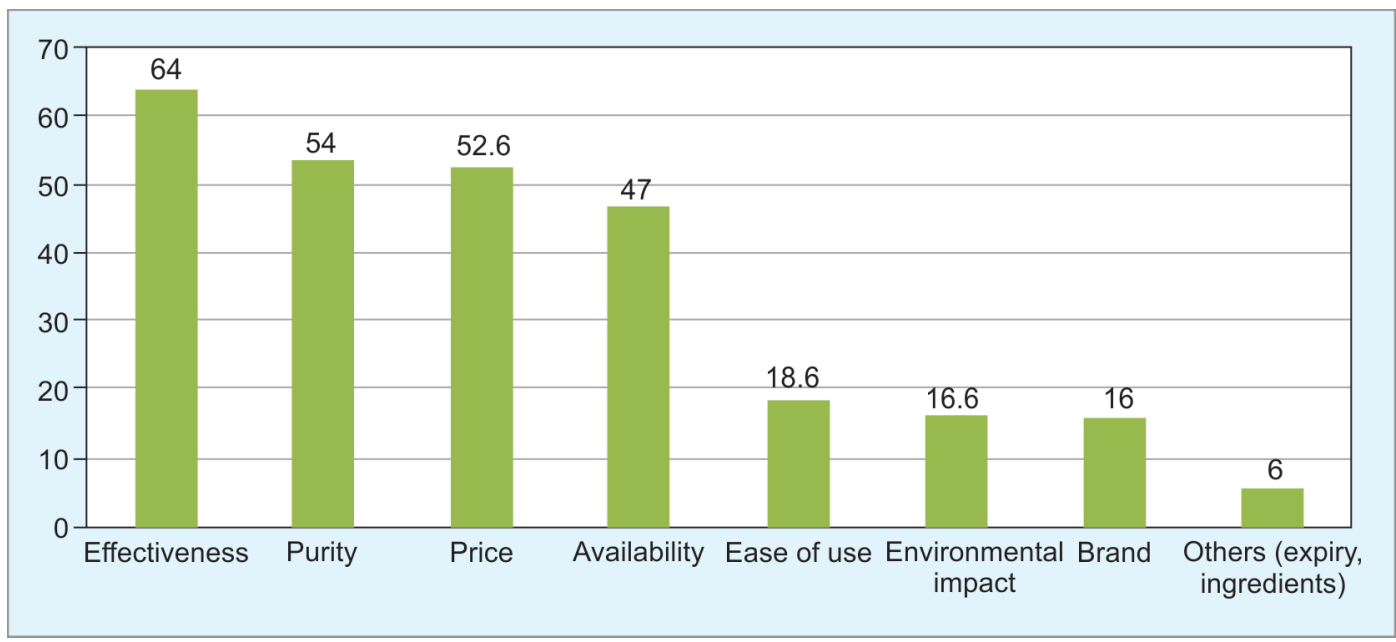

Fig. 2: Purchasing criteria that prompted buying of health and wellness products 
Table 3: Gender-, education-, and residence- wise frequency distribution of health and wellness product use score

\begin{tabular}{|c|c|c|c|c|c|}
\hline & \multicolumn{3}{|c|}{ Product usage score } & \multirow[b]{2}{*}{ Total } & \multirow[b]{2}{*}{ Chi-square; $p$ value, $d f 1$} \\
\hline & Low $21-40$ & Average 41-60 & High 61-100 & & \\
\hline \multicolumn{6}{|l|}{ Gender } \\
\hline \multirow[t]{2}{*}{ Male } & $29(39.7)$ & $41(56)$ & $03(4)$ & $73(48.6)$ & 21.133 \\
\hline & $(85)$ & $(47)$ & $(10)$ & & \\
\hline \multirow[t]{2}{*}{ Female } & $05(6.4)$ & $46(59.7)$ & $26(33.7)$ & $77(51)$ & \\
\hline & $(14.7)$ & $(52.8)$ & $(89.6)$ & & \\
\hline Total & 34 & 87 & 29 & 150 & $0.000^{* *}$ \\
\hline \multicolumn{6}{|l|}{ Education } \\
\hline \multirow[t]{2}{*}{ Graduation and below } & $25(29.7)$ & $48(57)$ & $11(13)$ & $84(56)$ & 4.767 \\
\hline & $(73.5)$ & $(55)$ & $(37.9)$ & & \\
\hline \multirow[t]{2}{*}{ Postgraduation and above } & $9(13.6)$ & $39(59)$ & $18(27)$ & $66(44)$ & \\
\hline & $(26)$ & $(44.8)$ & $(62)$ & & \\
\hline \multirow[t]{2}{*}{ Total } & 34 & 87 & 29 & 150 & $0.029^{* *}$ \\
\hline & Low $21-40$ & Average 41-60 & High 61-100 & Total & Chi-square; $p$ value, $d f 2$ \\
\hline \multicolumn{6}{|l|}{ Residence } \\
\hline \multirow[t]{2}{*}{ Chandigarh } & $30(30)$ & $51(51)$ & $19(19)$ & $100(66.6)$ & 8.972 \\
\hline & $(88)$ & $(58.6)$ & $(65.5)$ & & \\
\hline \multirow[t]{2}{*}{ Shimla } & $04(8)$ & $36(72)$ & $10(20)$ & $50(33)$ & \\
\hline & $(11.7)$ & $(41)$ & (34) & & \\
\hline Total & 34 & 87 & 29 & 150 & $0.011^{* *}$ \\
\hline
\end{tabular}

there has been an increased demand for fitness products like smartwatches, running shoes, green coffee, etc.

The factors that affect health according to the majority of participants were diet, environment, and genes. Diet has always been given importance in Indian tradition. Ancient science and medicine like Ayurveda focus on the importance of diet to stay healthy. ${ }^{8}$ In this study also, it was found that for remaining healthy the main emphasis given by the majority of participants was on taking a healthy diet and maintaining hygiene. It is also reflected by the high usage of products like ghee, butter, cornflakes, and nuts. This shows that the respondents put their knowledge into practice. Similar findings were reported in an article in The Economic Times which said that $48 \%$ of respondents were eating healthy to stay fit. ${ }^{9}$ The thought process of participants was in line with the health field theory which also says that health is affected by environment, lifestyle, environment, and genes. ${ }^{10}$ Regular medical checkup was not given much importance despite all the advertisements and promotion. This could be because of the fact in many instances women and the elderly have to depend on others for such consultation which requires a lot of money.

Consumers in general relied on various sources of information to learn about health and wellness products. Internet (70\%) was the most commonly used source by the majority of participants. Other sources used by many subjects were family members, newspapers, and commercials. The increased use of the Internet has forced many companies to develop interactive and informative websites to promote their products among consumers. The importance of books, magazines, and experts has somewhat reduced due to social media and the Internet. This is also reflected in the study as very few participants (5\%) used these sources of information.

The trend of buying health and wellness products online and from marts could also be seen. This could be a result of discounts and membership offers given by various brands to attract customers.
The most important criterion for purchasing any health and wellness product for the majority of participants was effectiveness followed by quality. This shows that people are willing to pay a little extra but without compromising the quality of products. On the other hand, half of the participants reported price as a criterion for buying a product. Few participants were concerned about the brand of the product. The use of branded products could be less due to their high prices. Very few participants reported product ingredients and expiry as important criteria for purchasing health and wellness products.

Females were found to be using more health and wellness products than males. They used more beauty care products when compared with males. This could be because more cosmetic products are marketed for women like lipsticks, eyeliner, nail color, etc. The facial beauty of females has always been given importance across the culture and time. ${ }^{11}$ Even in poetry, literature, songs "beautiful face and eyes" have been eulogized. "Whiteness" (gorapan) ${ }^{12}$ has also been promoted in advertisements, movies. This shows that there is a great impact of advertisements and cinema on the audience. This could be the main reason behind the increased use of skin lightening and fairness creams by people.

According to a study by PwC and FICCI people lying between the ages of 25 years and 49 years contribute toward high usage of wellness products. ${ }^{6}$ It said that this age group is receptive to products and services. This group of people is willing to pay a premium for high-quality products. ${ }^{6}$ In regard to total product usage score, age differences in usage were not seen in this study. The usage of products was almost equal in all age groups. People of higher age groups are also spending on these products. This depicts that there is an increase in concern and awareness about health among all age groups. This has promoted the launching of age-specific products in the market. 
The participants with post-graduate or higher degrees used more health and wellness products when compared with graduates. This shows that with an increase in education and knowledge, individuals are becoming more conscious about their health. It could be due to more income of people with higher educational status.

The use of health and wellness products was higher among participants belonging to Shimla when compared with Chandigarh. A very few residents of Shimla reported low usage of these products. Participants from Shimla used more diet and beauty care products. Females from Shimla used more color cosmetics. The use of fitness and hygiene products was seen more among the people of Chandigarh. It is quite likely due to more disposable income available with Shimla consumers.

\section{Recommendation}

A program should be launched by the government to provide full and authenticated information about the changing concepts of health and wellness and related products. Mechanisms need to be developed so that the benefits of these products reach the majority of people at affordable prices.

\section{Conclusion}

The factor that affected the use of these products was gender. Females were using more health and wellness products than males. The use of products was seen among all age groups. People equated health and wellness with physical fitness. Taking a proper diet was given more importance over all other activities to remain healthy. Internet was the most popular source of information regarding health and wellness. The effectiveness and price of a product were reported to be important criteria for purchasing products.

\section{References}

1. Strohecker J. A brief history of wellness. Wellness inventory 2005.

2. Life sciences \& IT knowledge banking (Isit), Yes bank, Health \& Wellness: Indian Perspective 2014.

3. Smith MN. Health; a purchasable commodity. Occup Health Nurs 1985;33(11):539-540. DOI: 10.1177/216507998503301101.

4. Krom K, Health \&Wellness is the Next Trillion Dollar Industry, Industry News: Health \& Wellness; 2016.

5. Akshar, Indian Wellness Industry rightfully deserves a "Make in India" impetus, ET Health world, The Economic Times; 2017.

6. PwC, FICCl: Winds of change, The wellness consumer; 2012.

7. The rise of wellcare: A new market at the nexus of health, food, and beauty, PwC Strategy\&; 2017.

8. Naryanaswamy V. Origin and development of ayurveda: (A brief history). Anc Sci Life 1981;1:1-7.

9. Nasline S, Fit and fine: Retail market for fitness in India likely to touch Rs 7,000cr by year-end, The Economic Times; 2017.

10. Lewin K. Resolving Social Conflicts \& Field Theory in Social Science. American Psychological Association; 2008.

11. Uku A, A timeline of beauty defined through the ages: The fashion spot; 2010.

12. Chatterjee S, Enough Of 'Gorapan', Let's Address The Darkness In Our Thoughts: Youth ki awaaz; 2018. 